\title{
Thermal analysis on multijunction photovoltaic cell under oblique incident laser irradiation
}

\author{
Chen-Wu Wu*, Qing Peng, Chen-Guang Huang \\ Institute of Mechanics, Chinese Academy of Sciences, Beijing 100190, China
}

\section{A R T I C L E I N F O}

\section{Article history:}

Received 22 October 2016

Received in revised form

5 April 2017

Accepted 4 June 2017

Available online 5 June 2017

\section{Keywords:}

Photovoltaic cell

Laser

Oblique incident

Thermal

\begin{abstract}
A B S T R A C T
Laser beam irradiation was modeled to investigate the thermal responses of multijunction photovoltaic cell to the irradiation of oblique incident monochromatic light. First, the monochromatic light absorption in multijunction photovoltaic cell is formulated with accounting for multiple reflections as well as interferences. Then, an iterative algorithm was established to calculate the depositions of incident laser energy in every layer. Finally, the temperature characteristics of the photovoltaic cell are analyzed with finite element method.
\end{abstract}

(C) 2017 Elsevier Ltd. All rights reserved.

\section{Introduction}

The light power conversion efficiency of the photovoltaic cell is largely dependent on its operation temperature, which results from the fact that the open circuit voltage would decrease apparently with the temperature elevation of the $p-n$ junctions [1]. The reduction of the open circuit voltage temperature rising would decrease the fill factor and hence the efficiency of the photovoltaic cell [2]. This is the case for the single junction solar cell as well as the multijunction solar cell $[3,4]$. As for the great temperature dependency of the efficiency, a two-stage hybrid solar cell is even proposed theoretically to improve the overall energy conversion efficiency, in which the thermoelectric effect could play a part after the cell temperature is above some value around $150{ }^{\circ} \mathrm{C}[5,6]$.

The dependency of the light-electrical conversion efficiency of a photovoltaic cell on its operating temperature is well documented, while the cell temperature, in particular the temperature pattern within the cell has not been always readily available for its design or operation [7].

Experimentally, the so-called photoluminescence technique was used to measure the junction temperature of the solar cells [8]. The junction temperature of the Mono-crystalline Si photovoltaic

\footnotetext{
* Corresponding author. Institute of Mechanics, Chinese Academy of Sciences, No. 15 BeisihuanXi Road, Beijing 100190, China.

E-mail addresses: chenwuwu@imech.ac.cn, c.w.wu@outlook.com (C.-W. Wu).
}

cell was estimated empirically through the measured output voltage of the cell and ambient temperature [9]. A set of models were compared to estimate the cell temperature, and the relevance between the cell temperature and open circuit voltage of the cell is further validated for Phaesun USP 10 modules [10]. The desires to theoretically describe the temperature characteristic of the photovoltaic cell have also boosted much work [11]. With assuming the heat generation to be evenly distributed in the single junction solar cell, the effects of the different ambient thermal boundaries were modeled to describe numerically the cell temperature under sunlight [12]. The temperature of the single solar cell was investigated numerically with finite element method with treating the inefficient light energy as heat flux through the cell surface without considering the inner structure of the cell $[13,14]$. The finite element method was also applied to the tripe junction solar cell, in which the heat dissipated from light energy was again assumed to be evenly distributed within the whole cell [15].

The $\mathrm{p}-\mathrm{n}$ junction temperature of the cell is determined by the equilibrium between the heat generation from the incident light energy and the heat diffused into the environment. The distributions of the heat generated by the incident light are determined by the reflection and absorption of the light in the multijunction photovoltaic cell. As we know, the refractive index and absorption coefficient of the materials depend on the wavelength of the incident light. Before now, the monochromatic light irradiation was devised to investigate the thermal behaviors of the photovoltaic cell and the thermal response of multijunction photovoltaic cell 


\begin{tabular}{|c|c|c|c|}
\hline \multicolumn{2}{|c|}{ Nomenclatures } & \multirow{2}{*}{ T } & \multirow{2}{*}{$\begin{array}{l}\text { effective transmittance from ith layer to kth layer } \\
\text { through jth layer } \\
\text { coefficient matrix for iteration }\end{array}$} \\
\hline A & amplitude of the electrical field & & \\
\hline E & light Energy, laser energy & w & number of the total effective layers of the cell structure \\
\hline $\mathbf{V}_{\mathbf{p}}$ & position vector & $\mathrm{T}_{\mathrm{emp}}$ & Temperature \\
\hline $\mathbf{V}_{\mathbf{w}}$ & unit wave vector of laser & $\mathrm{r}_{\mathrm{b}}$ & radius of laser beam \\
\hline$\theta$ & refractive angle & $r_{j x}, r_{j y}$ & semi-axis length of the elliptical laser spot for every \\
\hline$\theta_{0}$ & $\begin{array}{l}\text { the incident angle of the incident laser to the foremost } \\
\text { surface }\end{array}$ & $Q(x, y)$ & $\begin{array}{l}\text { layer } \\
\text { specific heat generation rate }\end{array}$ \\
\hline $\mathrm{n}$ & $\begin{array}{l}\text { refractive index and } \mathrm{n}=\left(\left(\varepsilon^{2} \mu^{2}+16 \pi^{2} \sigma^{2} \mu^{2} / \omega^{2}\right)^{1 /}\right. \\
2+\varepsilon \mu) / 2\end{array}$ & $\begin{array}{l}\mathrm{T}_{\mathrm{amb}} \\
\mathrm{T}_{\mathrm{ext}}\end{array}$ & $\begin{array}{l}\text { ambient temperature } \\
\text { outer fluid temperature }\end{array}$ \\
\hline $\mathrm{k}$ & $\begin{array}{l}\text { extinctive coefficient and } \mathrm{k}=\left(\left(\varepsilon^{2} \mu^{2}+16 \pi^{2} \sigma^{2} \mu^{2} / \omega^{2}\right)^{1 /}\right. \\
\left.{ }^{2}-\varepsilon \mu\right) / 2\end{array}$ & & $\begin{array}{l}\text { time } \\
\text { convective heat transfer coefficient }\end{array}$ \\
\hline$\varepsilon$ & dielectric permittivity & $\mathrm{x}, \mathrm{y}, \mathrm{z}$ & spatial coordinates \\
\hline$\mu$ & magnetic permeability & $\Delta$ & Laplace operator \\
\hline$\sigma$ & Electric conductivity & $\rho$ & density \\
\hline$\omega$ & angular frequency of laser & $c_{h}$ & specific heat capacity \\
\hline$\lambda_{0}$ & wave length of laser in free space $\left(=2 \pi c_{0} / \omega\right)$ & $\mathrm{k}_{\mathrm{th}}$ & thermal conductivity \\
\hline$c_{0}$ & $\begin{array}{l}\text { propagation velocity of electromagnetic wave in free } \\
\text { space }\end{array}$ & $\begin{array}{l}\beta \\
\varepsilon_{\mathrm{ie}}\end{array}$ & $\begin{array}{l}\text { thermal diffusivity defined by } \mathrm{k}_{\mathrm{th}}\left(\rho \mathrm{c}_{\mathrm{h}}\right)^{-1} \\
\text { infrared emittance }\end{array}$ \\
\hline $\begin{array}{l}\alpha \\
\mathrm{u}\end{array}$ & $\begin{array}{l}\text { absorption coefficient and } \alpha=4 \pi \mathrm{k} / \lambda_{0} \\
\text { imaginary unit defined by } \mathrm{u}^{2}=-1\end{array}$ & $\sigma_{\mathrm{sb}}$ & Stefan-Boltzmann constant $\left(=5.67 \mathrm{e}-8 \mathrm{Wm}^{-2} \mathrm{~K}^{-1}\right)$ \\
\hline $\mathrm{n}_{0}$ & refractive index of air to incident laser $(\approx 1)$ & superscr & pts or subscripts \\
\hline d & layer thickness & $P$ & parallel component of the incident electrical vector \\
\hline $\mathrm{r}_{\mathrm{ij}}$ & $\begin{array}{l}\text { Fresnel reflection coefficient at interface from ith layer } \\
\text { to jth layer }\end{array}$ & $S$ & $\begin{array}{l}\text { perpendicular component of the incident electrical } \\
\text { vector }\end{array}$ \\
\hline$t_{i j}$ & $\begin{array}{l}\text { Fresnel transmission coefficient at interface from ith } \\
\text { layer to ith laver }\end{array}$ & $\begin{array}{l}r \\
t\end{array}$ & $\begin{array}{l}\text { reflected component } \\
\text { transmitted component }\end{array}$ \\
\hline $\mathrm{R}$ & $\begin{array}{l}\text { effective reflectance at interface from ith layer to jth } \\
\text { layer }\end{array}$ & $\begin{array}{l}\mathrm{m}, \mathrm{j}, \mathrm{k} \\
\mathrm{i} \rightarrow \mathrm{j}\end{array}$ & $\begin{array}{l}\text { sequence number } \\
\text { layer sequence number with } \mathrm{i}=\mathrm{j}-1 \text { and } \mathrm{k}=\mathrm{j}+1 \\
\text { from ith layer to } \mathrm{jth} \text { layer }\end{array}$ \\
\hline
\end{tabular}

subjected to vertically incident laser beam irradiation was preliminarily discussed [16]. However, it is understandable that the inclination angle of the oblique incident laser should be of crucial importance as far as the multiple reflections and refractions of the light across the interfaces are taken into account.

The thermal responses of multijunction photovoltaic cell to the irradiation of oblique incident monochromatic light, i.e. the laser beam, were investigated in this study. The multiple interface reflections as well as interferences of monochromatic light in multilayer films were particularly formulated to calculate laser absorption in the multijunction photovoltaic cell. An iterative algorithm was established to realize the calculation of the laser absorption in every layer and, the heat conduction equation controlling the temperature of the photovoltaic cell are solved by finite element method as a numerical example for typical parameter combination.

\section{Formula}

The reflection, transmittance as well as absorption in an arbitrary inner layer could be analyzed and then extended to formulate the multiple interface reflections and interferences of laser transmitted in the multijunction photovoltaic cell. As for any arbitrary inner layer, the absorbed laser energy equals to the input laser energy from both boundaries subtracting that escaped from both boundaries, at which the interference could arise and its effect should be taken into account. First of all, one can consider such flowing pattern of the laser energy $E_{\{i \rightarrow j\}}$ from the ith layer numbered $\mathrm{i}$ to the jth layer numbered $\mathrm{j}$ as shown in Fig. 1.
The inclination angle of the light to the interface in any jth layer could be quickly determined by the Snell laws [17] as

$\mathrm{n}_{\mathrm{j}} \sin \theta_{\mathrm{j}}=\mathrm{n}_{0} \sin \theta_{0}$.

The electrical component of the incident laser from ith to jth layer is [17]

$A_{i \rightarrow j} \exp \left(u\left(\omega \mathrm{t}-\mathrm{n}_{i} \mathbf{V}_{\mathrm{W}} \cdot \mathbf{V}_{\mathrm{p}} / \mathrm{c}_{0}\right)\right)$

The amplitudes of the multiply reflected electrical components of the incident laser could be written as

$A_{1}^{r}=r_{i j} A_{i \rightarrow j}$,

and

$A_{m}^{r}=t_{i j}\left(r_{j k} e^{-2 \xi_{j}}\right)^{m-1}\left(r_{j i}\right)^{m-2} t_{j i} e^{-u 2(m-1) \delta_{j}} A_{i \rightarrow j}, \mathrm{~m}=2,3,,$,

To make a vector addition and get the resultant amplitude of all reflected electrical vectors as

$A^{r}(j)=\sum_{m=1}^{\infty} A_{m}^{r}=\left(r_{i j}+\frac{t_{i j} t_{j i} r_{j k} e^{-2 \xi_{i}} e^{-u 2 \delta_{i}}}{1-r_{j k} r_{j i} e^{-2 \xi_{i}} e^{-u 2 \delta_{i}}}\right) A_{i \rightarrow j}$.

By utilizing the law of reversibility and energy conservation at the interface

$r_{j i}=-r_{i j}$ and $t_{i j} t_{j i}=1-\left(r_{i j}\right)^{2}$, 


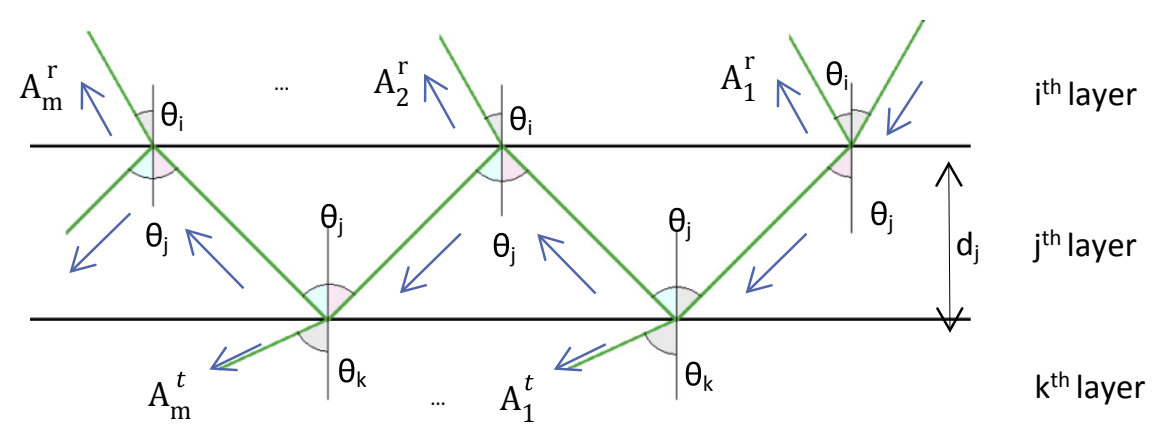

Fig. 1. Light energy flowing chart for any monolayer.

One can immediately get the amplitude ratio of the reflected to the incident as

$\frac{A^{r}(j)}{A_{i \rightarrow j}}=\frac{r_{i j}+r_{j k} e^{-2 \xi_{j}} e^{-u 2 \delta_{j}}}{1+r_{i j} r_{j k} e^{-2 \xi_{j}} e^{-u 2 \delta_{j}}}$

where,

$\delta_{j}=\frac{2 \pi}{\lambda_{0}} n_{j} d_{j} \cos \theta_{j}$

$\xi_{j}=\frac{2 \pi k_{j}}{\lambda_{0}} \frac{d_{j}}{\cos \theta_{j}}=\frac{\alpha_{i}}{2} \frac{d_{j}}{\cos \theta_{j}}$.

Therefore, the effective reflectance of the incident laser energy flux at the interface from ith layer to jth layer is

$R_{i j}\left(\delta_{j}, \xi_{j} ; r_{i j}\right)=\left|\frac{A^{r}(j)}{A_{i \rightarrow j}}\right|^{2}=\frac{r_{i j}^{2}+r_{j k}^{2} e^{-4 \xi_{1}}+2 r_{i j} r_{j k} e^{-2 \xi_{1}} \cos 2 \delta_{j}}{1+\left(r_{i j} r_{j k}\right)^{2} e^{-4 \xi_{1}}+2 r_{i j} r_{j k} e^{-2 \xi_{1}} \cos 2 \delta_{j}}$.

where the Fresnel reflection coefficient at the interface between ith layer and jth layer for p-polarized wave and s-polarized wave of the incident light are [17]

$r_{i j}^{P}=\frac{\tan \left(\theta_{j}-\theta_{i}\right)}{\tan \left(\theta_{j}+\theta_{i}\right)}$

and

$r_{i j}^{S}=\frac{\sin \left(\theta_{j}-\theta_{i}\right)}{\sin \left(\theta_{j}+\theta_{i}\right)}$,

respectively. Substitute (10) or (11) into (9), one can get

$R_{i j}^{P}\left(\delta_{j}, \xi_{j}\right)=R\left(\delta_{j}, \xi_{j} ; r_{i j}^{P}\right)$

and

$R_{i j}^{S}\left(\delta_{j}, \xi_{j}\right)=R\left(\delta_{j}, \xi_{j} ; r_{i j}^{S}\right)$

respectively. Then, the overall effective reflectance at the interface from ith layer to jth layer for a randomly polarized laser is [17]

$R_{i j}\left(\delta_{j}, \xi_{j}\right)=\frac{1}{2}\left(R_{i j}^{P}\left(\delta_{j}, \xi_{j}\right)+R_{i j}^{S}\left(\delta_{j}, \xi_{j}\right)\right)$.
At the same time, the amplitudes of the multiply transmitted electrical components of the incident laser from ith lth layer to kth layer through jth layer could be written as

$A_{m}^{t}=t_{i j}\left(r_{j k} r_{j i}\right)^{m-1} t_{j k} e^{-u(2 m-1) \delta_{j}} e^{-(2 m-1) \xi_{j}} A_{i \rightarrow j}, \quad \mathrm{~m}=1,2,3,,$,

Therefore, by taking vector addition again one can obtain the amplitude of the resultant amplitude of all transmitted electrical vector as

$A^{t}(j)=\sum_{m=1}^{\infty} A_{m}^{t}=\frac{t_{i j} t_{j k} e^{-u \delta_{j}} e^{-\xi_{j}}}{1-r_{i j} r_{j k} e^{-u 2 \delta_{1}} e^{-2 \xi_{1}}} A_{i \rightarrow j}$

The effective transmittance of the incident Laser energy flux across the interface between ith layer and jth layer to the kth layer is

$$
\begin{aligned}
T_{i j}\left(\delta_{j}, \xi_{j} ; r_{i j}, t_{i j}\right) & =\left|\frac{A^{t}(j)}{A_{i \rightarrow j}}\right|^{2} \\
& =\frac{t_{i j}^{2} t_{j k}^{2} e^{-2 \xi_{j}}}{1+\left(r_{i j} r_{j k}\right)^{2} e^{-4 \xi_{1}}-2 r_{i j} r_{j k} e^{-2 \xi_{1}} \cos 2 \delta_{j}}
\end{aligned}
$$

where, the Fresnel transmission coefficient at the interface between ith media and jth media for p-polarized wave and s-polarized wave of the incident light are [17]

$t_{i j}^{P}=\frac{2 \sin \theta_{j} \cos \theta_{i}}{\sin \left(\theta_{i}+\theta_{j}\right) \cos \left(\theta_{i}-\theta_{j}\right)}$

and

$t_{i j}^{S}=\frac{2 \sin \theta_{j} \cos \theta_{i}}{\sin \left(\theta_{i}+\theta_{j}\right)}$

respectively. Substitute (18) or (19) into (17), one can get

$T_{P}\left(\delta_{j}, \xi_{j}\right)=T\left(\delta_{j}, \xi_{j} ; r_{i j}^{P}\right)$

and

$T_{S}\left(\delta_{j}, \xi_{j}\right)=T\left(\delta_{j}, \xi_{j} ; r_{i j}^{S}\right)$

respectively. Then, the overall effective transmittance from ith layer to kth layer through jth for a randomly polarized laser is [17] 
$T_{i j}(\delta, \xi)=\frac{1}{2}\left(T_{P}+T_{S}\right)$

Now, the escaped part of the input laser energy $E_{i \rightarrow j}$ from ith layer to jth layer across the interface between ith layer and jth layer after multiple reflections could be written as

$\mathrm{E}_{\{\mathrm{j} \rightarrow \mathrm{i} \text { in } \mathrm{i} \rightarrow \mathrm{j}\}}=\mathrm{E}_{\{\mathrm{i} \rightarrow \mathrm{j}\}} \mathrm{R}_{\mathrm{ij}}\left(\delta_{\mathrm{j}}, \xi_{\mathrm{j}}\right)$,

And, the escaped part of the input laser energy $E_{i \rightarrow j}$ from ith layer to jth layer across the interface between jth layer and kth layer could be written as

$\mathrm{E}_{\{\mathrm{j} \rightarrow \mathrm{k} \text { in } \mathrm{i} \rightarrow \mathrm{j}\}}=\mathrm{E}_{\{\mathrm{i} \rightarrow \mathrm{j}\}} \mathrm{T}_{\mathrm{ij}}\left(\delta_{\mathrm{j}}, \xi_{\mathrm{j}}\right)$.

Thus, the absorbed part of the input laser energy $E_{i \rightarrow j}$ from ith layer to $\mathrm{jth}$ layer by the $(\mathrm{j})^{\text {th }}$ layer could be obtained as

$\mathrm{E}_{\{\alpha(\mathrm{j}) \text { in } \mathrm{i} \rightarrow \mathrm{j}\}}=\mathrm{E}_{\{\mathrm{i} \rightarrow \mathrm{j}\}}\left(1-\mathrm{R}_{\mathrm{ij}}\left(\delta_{\mathrm{j}}, \xi_{\mathrm{j}}\right)-\mathrm{T}_{\mathrm{ij}}\left(\delta_{\mathrm{j}}, \xi_{\mathrm{j}}\right)\right)$,

Similarly, one can obtain the three parts of the input laser energy from kth layer to the jth layer as

$\mathrm{E}_{\{\mathrm{j} \rightarrow \mathrm{i} \text { in } \mathrm{k} \rightarrow \mathrm{j}\}}=\mathrm{E}_{\{\mathrm{k} \rightarrow \mathrm{j}\}} \mathrm{T}_{\mathrm{kj}}\left(\delta_{\mathrm{j}}, \xi_{\mathrm{j}}\right)$,

$\mathrm{E}_{\{\mathrm{j} \rightarrow \mathrm{k} \text { in } \mathrm{k} \rightarrow \mathrm{j}\}}=\mathrm{E}_{\{\mathrm{k} \rightarrow \mathrm{j}\}} \mathrm{R}_{\mathrm{kj}}\left(\delta_{\mathrm{j}}, \xi_{\mathrm{j}}\right)$.

$\mathrm{E}_{\{\alpha(\mathrm{j}) \text { in } \mathrm{k} \rightarrow \mathrm{j}\}}=\mathrm{E}_{\{\mathrm{k} \rightarrow \mathrm{j}\}}\left(1-\mathrm{T}_{\mathrm{kj}}\left(\delta_{\mathrm{j}}, \xi_{\mathrm{j}}\right)-\mathrm{R}_{\mathrm{kj}}\left(\delta_{\mathrm{j}}, \xi_{\mathrm{j}}\right)\right)$,

Therefore, the energy parts that absorbed by any inner jth layer or escaped from its both boundaries from the input laser energy at both sides could be described as

$\left[\mathrm{E}_{\{\mathrm{j} \rightarrow \mathrm{i}\}} \mathrm{E}_{\{\mathrm{j} \rightarrow \mathrm{k}\}} \mathrm{E}_{\{\alpha(\mathrm{j})\}}\right]=\left[\mathrm{E}_{\{\mathrm{i} \rightarrow \mathrm{j}\}} \mathrm{E}_{\{\mathrm{k} \rightarrow \mathrm{j}\}}\right] \mathbf{G}^{\{\mathrm{j}\}}$,

wherein the transfer coefficient matrix $\mathbf{G}^{\{\mathbf{j}\}}$ is

$G^{\{j\}}=\left[\begin{array}{lll}G_{11}^{\{j\}} & G_{12}^{\{j\}} & G_{13}^{\{j\}} \\ G_{21}^{\{j\}} & G_{22}^{\{j\}} & G_{23}^{\{j\}}\end{array}\right]$,

with

$G_{11}^{\{j\}}=\mathrm{R}_{\mathrm{ij}}\left(\delta_{\mathrm{j}}, \xi_{\mathrm{j}}\right)$

$G_{21}^{\{j\}}=\mathrm{T}_{\mathrm{kj}}\left(\delta_{\mathrm{j}}, \xi_{\mathrm{j}}\right)$

$G_{12}^{\{j\}}=\mathrm{T}_{\mathrm{ij}}\left(\delta_{\mathrm{j}}, \xi_{\mathrm{j}}\right)$

$G_{22}^{\{j\}}=\mathrm{R}_{\mathrm{kj}}\left(\delta_{\mathrm{j}}, \xi_{\mathrm{j}}\right)$

$G_{13}^{\{j\}}=1-\mathrm{R}_{\mathrm{ij}}\left(\delta_{\mathrm{j}}, \xi_{\mathrm{j}}\right)-\mathrm{T}_{\mathrm{ij}}\left(\delta_{\mathrm{j}}, \xi_{\mathrm{j}}\right)$,

and

$G_{23}^{\{j\}}=1-\mathrm{T}_{\mathrm{kj}}\left(\delta_{\mathrm{j}}, \xi_{\mathrm{j}}\right)-\mathrm{R}_{\mathrm{kj}}\left(\delta_{\mathrm{j}}, \xi_{\mathrm{j}}\right)$

Now, one can image that the laser energy escaped from any jth layer across one of its interfaces should be equal to that entering into the adjacent layer sharing the same interface. Obviously, the air surrounding should be treated as the neighbor of the top and bottom layers of the cell. Therefore, the above expressions of laser energy absorbed by a single layer and escaped across its boundaries

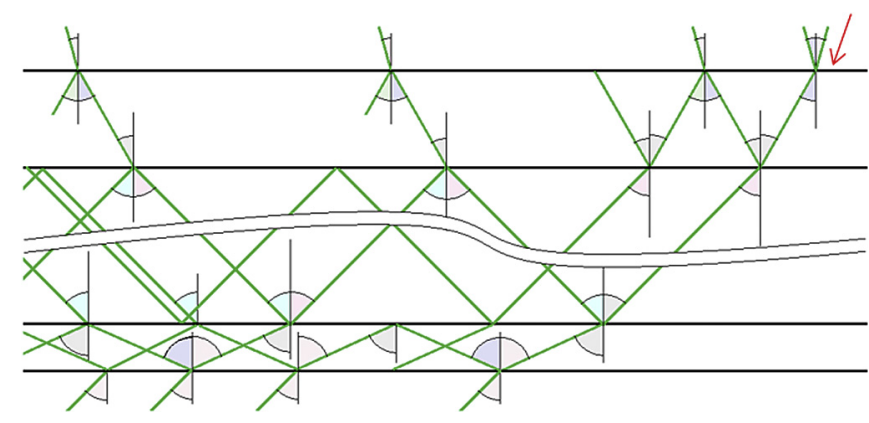

Fig. 2. Sketch of light energy flowing in the multilayer structure.

could be extended to all layers in the multilayer structure of a multijunction solar cell as shown in Fig. 2.

The generalized formulae are

$\left\{\mathrm{F}_{\mathrm{e}}\right\}=\left\{\mathrm{E}_{\mathrm{j}}\right\}\left[G^{\{e\}}\right]$,

And

$\left\{\mathrm{F}_{\mathrm{a}}\right\}=\left\{\mathrm{E}_{\mathrm{j}}\right\}\left[G^{\{a\}}\right]$.

where,

$$
\begin{aligned}
\left\{\mathrm{F}_{\mathrm{e}}\right\}= & \left\{\mathrm{E}_{\{1 \rightarrow 0\}} \mathrm{E}_{\{1 \rightarrow 2\}} \ldots \mathrm{E}_{\{\mathrm{j} \rightarrow \mathrm{j}-1\}} \mathrm{E}_{\{\mathrm{j} \rightarrow \mathrm{j}+1\}} \ldots \mathrm{E}_{\{\mathrm{w} \rightarrow \mathrm{w}-1\}}\right. \\
& \left.\mathrm{E}_{\{\mathrm{w} \rightarrow \mathrm{w}+1\}}\right\}, \\
\left\{\mathrm{E}_{\mathrm{j}}\right\}= & \left\{\mathrm{E}_{\{0 \rightarrow 1\}} \mathrm{E}_{\{2 \rightarrow 1\}} \ldots \mathrm{E}_{\{\mathrm{j}-1 \rightarrow \mathrm{j}\}} \mathrm{E}_{\{\mathrm{j}+1 \rightarrow \mathrm{j}\}}\right\} \ldots \mathrm{E}_{\{\mathrm{w}-1 \rightarrow \mathrm{w}\}} \\
& \left.\mathrm{E}_{\{\mathrm{w}+1 \rightarrow \mathrm{w}\}}\right\},
\end{aligned}
$$

$\left\{\mathrm{F}_{\mathrm{a}}\right\}=\left\{\mathrm{E}_{\{\alpha(1)\}} \cdots \mathrm{E}_{\{\alpha(\mathrm{j})\}} \cdots \mathrm{E}_{\{\alpha(\mathrm{w})\}}\right\}$,

$[G]=\left[\begin{array}{lllll}G_{1} & & & & \\ & \ldots & & & \\ & & G_{j} & & \\ & & & \ldots & \\ & & & & G_{w}\end{array}\right]$,

with

$G_{j}^{\{e\}}=\left[\begin{array}{ll}G_{11}^{\{j\}} & G_{12}^{\{j\}} \\ G_{21}^{\{j\}} & G_{22}^{\{j\}}\end{array}\right]$

and

$G_{j}^{\{a\}}=\left[\begin{array}{l}G_{13}^{\{j\}} \\ G_{23}^{\{j\}}\end{array}\right]$,

The expressions in the equations from (31) to (36) should be utilized by replacing ' $\mathrm{i}$ ' and ' $\mathrm{k}$ ' with ' $\mathrm{j}-1$ ' and ' $\mathrm{j}+1$ ', respectively. The ' 0 , th layer and ' $w+1^{\text {'th }}$ layer refer to the air surrounding and, the items $\mathrm{E}_{\{1 \rightarrow 0\}}$ and $\mathrm{E}_{\{\mathrm{w} \rightarrow \mathrm{w}+1\}}$ in (39) account for the laser energy escaped from the top and bottom of the cell to the surrounding, respectively. The input energy by laser beam are the very terms $E_{\{0 \rightarrow 1\}}$ and $E_{\{w+1 \rightarrow w\}}$ in (40), one of which should be zero if only single side of the photovoltaic cell is irradiated.

Now, one can get the numerical solutions for the laser energy absorbed in every layer as implicitly expressed in Equations (38) and (41) based on the iterative algorithm as shown in Fig. 3, 


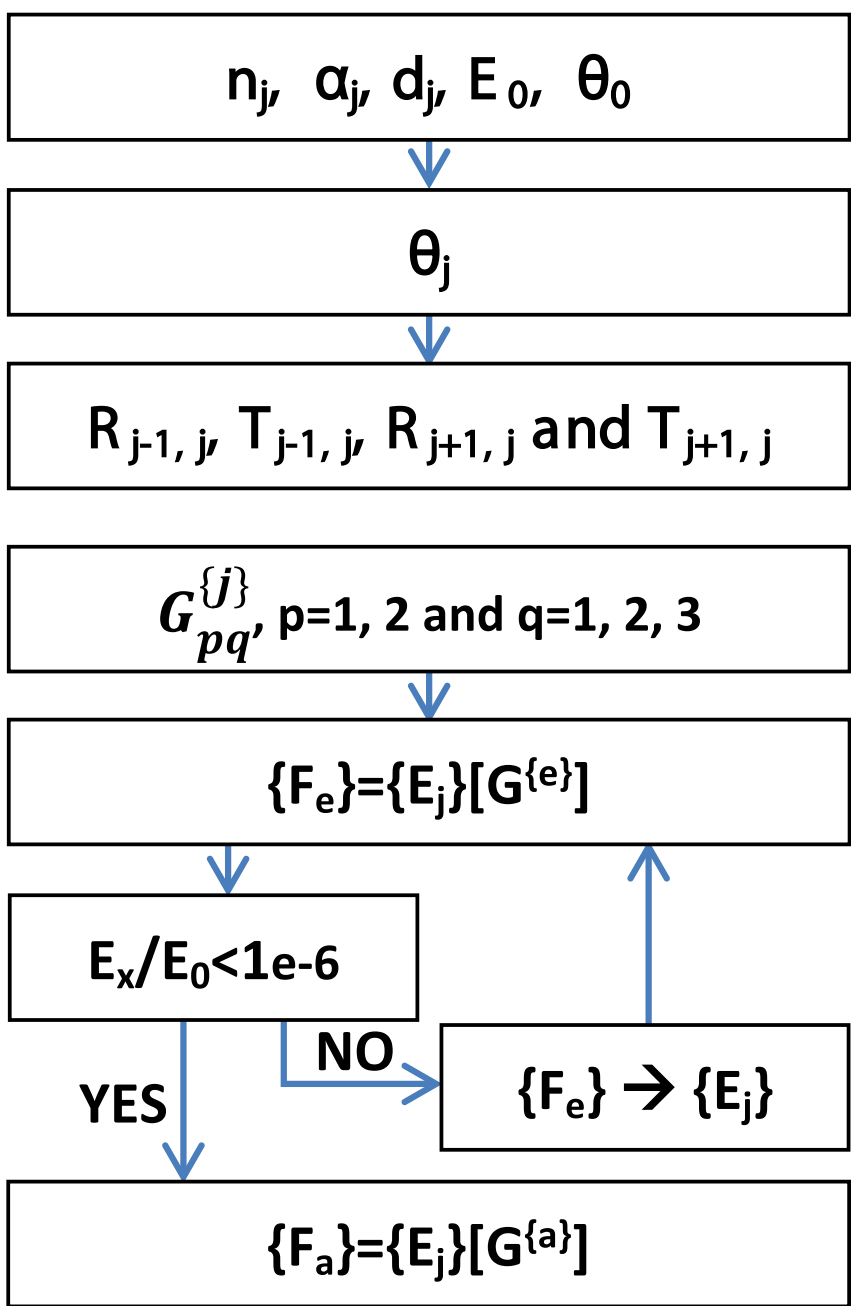

Fig. 3. The iterative algorithm.

which primarily involves the following four steps:

1) Calculate the refractive angle in each jth layer, the effective reflectance $R$ at each interface, the effective transmittance $T$ for every layer and the coefficient matrix $\left[G^{\mathrm{e}}\right]$ and $\left[\mathrm{G}^{\mathrm{a}}\right]$ for iteration.

2) Let $E_{\{0 \rightarrow 1\}}=E\left(1-R_{1,0}\right)$ refers to the laser energy inputted through the foremost surface to the first layer and $\mathrm{E}_{\{w+1 \rightarrow \mathrm{w}\}}=0$, which means that there is no laser energy entering the last layer from surrounding.

3) Compute (37) and (38), calculate the energy difference between the incident energy and the sum of absorbed energy and escaped energy,

$\mathrm{E}_{\mathrm{X}}=\left|\mathrm{E}-\sum_{j=1}^{w} \mathrm{E}\{\alpha(j)\}-\mathrm{E}_{\{1 \rightarrow 0\}}-\mathrm{E}_{\{\mathrm{w} \rightarrow \mathrm{w}+1\}}\right|$.

4) Judge whether the inequality

$\mathrm{E}_{\mathrm{X}} / \mathrm{E}_{0}<1 e-6$,

holds. If so, output $\left\{\mathrm{F}_{\mathrm{a}}\right\}=\left\{\mathrm{E}_{\{\alpha(1)\}} \ldots \mathrm{E}_{\{\alpha(\mathrm{j})\}} \ldots \mathrm{E}_{\{\alpha(\mathrm{w})\}}\right\}$. Otherwise, update the incident array $\left\{\mathrm{E}_{\mathrm{i}}\right\}$ by replacing it with $\left\{\mathrm{F}_{\mathrm{e}}\right\}$ and repeat the 4th step.
Table 1

Thickness and optical properties for every layer.

\begin{tabular}{|c|c|c|c|c|c|c|c|}
\hline \multirow[t]{2}{*}{ Layer No. } & \multirow[t]{2}{*}{$\mathrm{d}_{\mathrm{j}}(\mu \mathrm{m})$} & \multicolumn{3}{|c|}{$\alpha_{\mathrm{j}}\left(\mu \mathrm{m}^{-1}\right)$ for $\lambda($ in $n m)=$} & \multicolumn{3}{|c|}{$\mathrm{n}_{\mathrm{j}}$ for $\lambda($ in $\mathrm{nm})=$} \\
\hline & & 1064 & 532 & 266 & 1064 & 532 & 266 \\
\hline 01 & $4.0 \mathrm{E}-02$ & $1.0 \mathrm{E}-01$ & $2.0 \mathrm{E}-01$ & $2.6 \mathrm{E}-01$ & 1.8 & 2.0 & 1.9 \\
\hline 02 & $1.5 \mathrm{E}+00$ & $5.1 \mathrm{E}-05$ & $1.0 \mathrm{E}-04$ & $1.3 \mathrm{E}-04$ & 3.2 & 3.7 & 3.3 \\
\hline 03 & $3.0 \mathrm{E}-02$ & $9.7 \mathrm{E}-01$ & $1.9 \mathrm{E}+00$ & $2.5 \mathrm{E}+00$ & 3.1 & 3.5 & 3.4 \\
\hline 04 & $6.0 \mathrm{E}-03$ & $6.5 \mathrm{E}-05$ & $1.3 \mathrm{E}-04$ & $1.7 \mathrm{E}-04$ & 3.3 & 3.6 & 3.8 \\
\hline 05 & $6.0 \mathrm{E}-03$ & $2.8 \mathrm{E}-01$ & $5.6 \mathrm{E}-01$ & $7.3 \mathrm{E}-01$ & 3.6 & 4.2 & 2.8 \\
\hline 06 & $3.0 \mathrm{E}-02$ & $9.7 \mathrm{E}-01$ & $1.9 \mathrm{E}+00$ & $2.5 \mathrm{E}+00$ & 3.1 & 3.5 & 3.4 \\
\hline 07 & $7.5 \mathrm{E}+00$ & $2.8 \mathrm{E}-01$ & $5.6 \mathrm{E}-01$ & $7.3 \mathrm{E}-01$ & 3.6 & 4.2 & 2.8 \\
\hline 08 & $6.0 \mathrm{E}-03$ & $6.5 \mathrm{E}-05$ & $1.3 \mathrm{E}-04$ & $1.7 \mathrm{E}-04$ & 3.3 & 3.6 & 3.8 \\
\hline 09 & $6.0 \mathrm{E}-03$ & $2.8 \mathrm{E}-01$ & $5.6 \mathrm{E}-01$ & $7.3 \mathrm{E}-01$ & 3.6 & 4.2 & 2.8 \\
\hline 10 & $1.6 \mathrm{E}+02$ & $1.4 \mathrm{E}+00$ & $2.7 \mathrm{E}+00$ & $3.6 \mathrm{E}+00$ & 4.4 & 4.9 & 1.6 \\
\hline
\end{tabular}

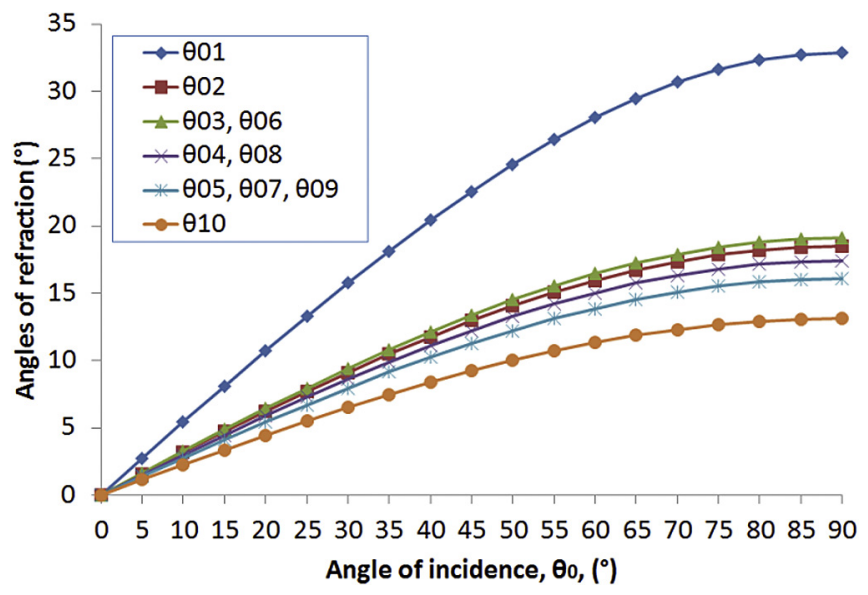

Fig. 4. Refractive angles in every layer for different incident angles.

\section{Numerical example}

The typical geometrical parameters and optical properties used in the numerical example are listed in Table 1 for the multijunction photovoltaic cells under irradiation by laser of wavelength $1064 \mathrm{~nm}, 532 \mathrm{~nm}$ or $266 \mathrm{~nm}$. It is noteworthy that the property constants have been indirectly obtained by interpolation and conversion based on the available materials database [18-20].

The angles of refraction could be calculated by (1) according to the Snell laws [17] and the outcomes for different angles of incidence are diagramed in Fig. 4.

One can find out that there are only six distinctive angles of refraction and no total reflectance at any interface when the angles of incidence change from 0 to $90^{\circ}$, which should be the case under the assumption of linear optical behaviors.

The absorbed light energy fractions for every layer are shown in Fig. 5, in which the dependency on the incident angles is mostly demonstrated.

It is indicated that the 7th layer absorbed the biggest percentage of the incident laser energy for the present case. That is mainly due to the fact that the 7th layer has relatively large absorptivity and large thickness. Therefore, large portion of the incident laser would be intercepted by this layer. Furthermore, the absorbed light energy would be altered by the angle of incidence as the reflective coefficients at the interfaces are strongly dependent on the refraction angles. It is revealed that the overall absorbed laser energy would be gradually increased with the increasing of the incident angles and maximized at some incident angle, which is in consistence with the Brewster angle in physics [17]. After that, the overall absorption might be sharply reduced to zero when the incident angle is $90^{\circ}$, which 


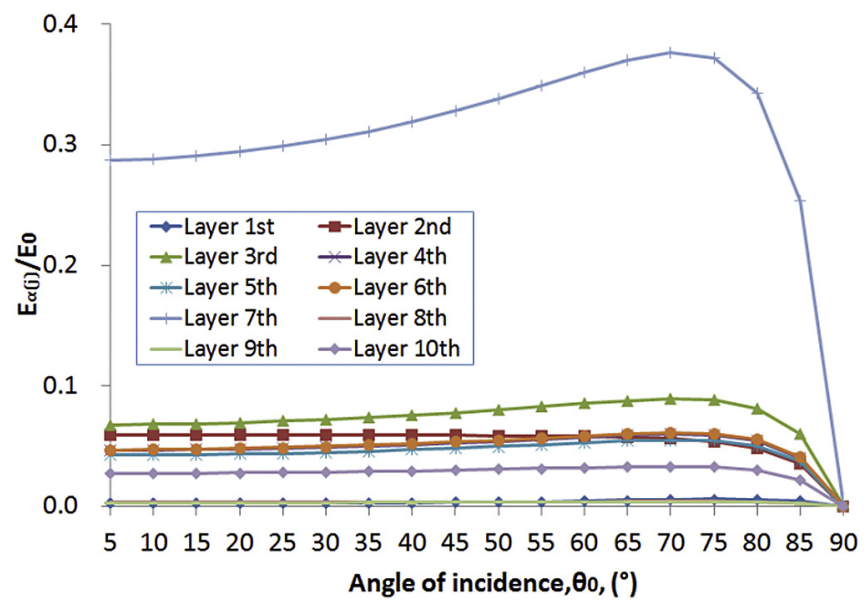

Fig. 5. Absorbed energy fractions in every layer for different incident angles.

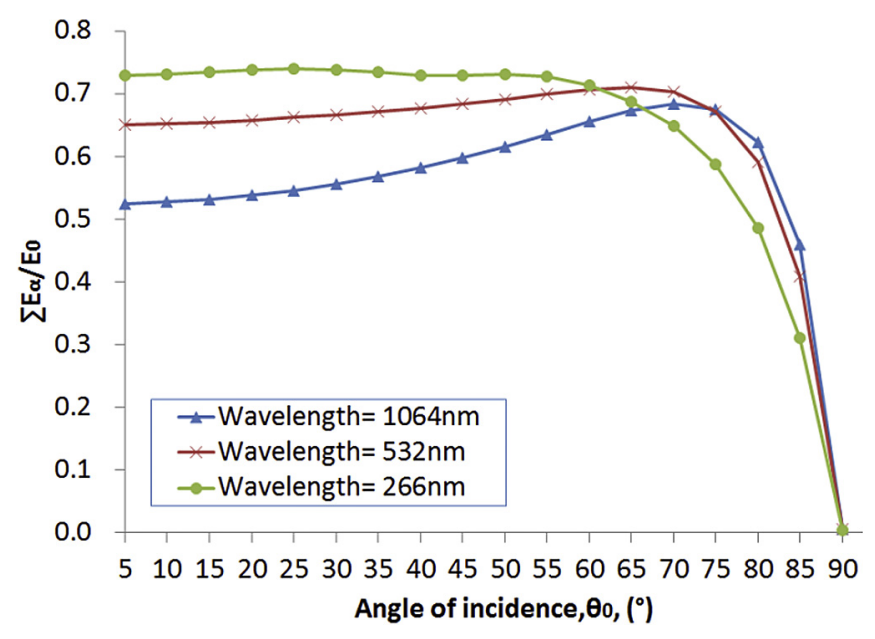

Fig. 6. Total absorbed energy fractions for different wavelengths.

means that the incident laser beam is parallel to the cell surface.

The total absorbed energy fraction, $\Sigma \mathrm{E}_{\alpha} / \mathrm{E}_{0}$ in the whole photovoltaic cell could be obtained by summing up all of that absorbed by each layer. The dependency on the wavelength of incident laser is calculated and shown in Fig. 6, to which the contribution of the interference is mostly revealed.

It is indicated that the total absorbed energy fraction, $\Sigma \mathrm{E}_{\alpha} / \mathrm{E}_{0}$ would increase with the decreasing of the laser wavelength. It is also indicated that the total absorbed energy fraction would change more smoothly in relative to the incident angles for the incident of relatively short wavelength. For instance, the effect of Brewster angle on maximizing the absorption would be almost invisible for wavelength is about $266 \mathrm{~nm}$ as shown in Fig. 6. The overall absorption of the incident laser with short wavelength is larger in comparison to that of long wavelength when the incident angle is smaller than $60^{\circ}$.

\section{Finite element analysis}

Assume the power of the incident Laser is $10 \mathrm{w}$ and the angle of incidence is $30^{\circ}$, one can obtain the absorbed laser power in every layer $E_{\alpha(j)}$ by multiplying the fractions shown in Fig. 5 by 10w, for which the energy distribution $\mathrm{E}_{\alpha(\mathrm{j})}$ and refraction angles $\theta_{\mathrm{j}}$ are listed in Table 2.

As shown in Fig. 7, the half geometry of photovoltaic cell of ten layer structure was modeled to carry through the Finite Element
Table 2

Deposited energy, refractive angles and thermal properties for every layer.

\begin{tabular}{llllll}
\hline Layer No. & $\theta_{\mathrm{j}}\left(^{\circ}\right)$ & $\mathrm{E}_{\alpha(\mathrm{j})}(\mathrm{W})$ & $\rho\left(\mathrm{kg} \mathrm{m}^{-3}\right)$ & $\mathrm{c}_{\mathrm{h}}\left(\mathrm{JK} \mathrm{g}^{-1} \mathrm{~K}^{-1}\right)$ & $\mathrm{K}_{\mathrm{th}}\left(\mathrm{Wm}^{-1} \mathrm{~K}^{-1}\right)$ \\
\hline 01 & 15.75 & 0.03 & 4815 & 279 & 57 \\
02 & 9.12 & 0.60 & 4785 & 279 & 55 \\
03 & 9.41 & 0.72 & 4795 & 279 & 60 \\
04 & 8.61 & 0.49 & 5320 & 330 & 55 \\
05 & 7.95 & 0.45 & 5680 & 250 & 27 \\
06 & 9.41 & 0.50 & 4795 & 279 & 60 \\
07 & 7.95 & 3.05 & 5680 & 250 & 27 \\
08 & 8.61 & 0.04 & 5320 & 330 & 55 \\
09 & 7.95 & 0.03 & 5680 & 250 & 27 \\
10 & 6.51 & 0.29 & 5323 & 310 & 60 \\
\hline
\end{tabular}

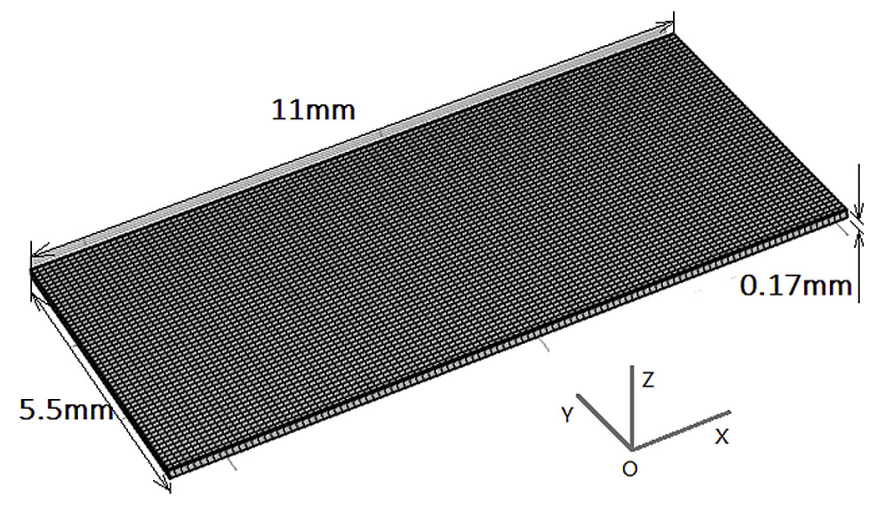

Fig. 7. Discretized geometrical model.

Analysis in the commercial software Comsol-Multiphysics considering the symmetrical characteristic of the present physical state. The half symmetrical geometry is discretized into 108, 900 elements to obtain the final convergent solution.

The in-plane dimension of the cell is $11 \mathrm{~mm} \times 5.5 \mathrm{~mm}$ and the thicknesses, $d_{i}$ are referred to Table 1 . The modified Gaussian distribution of energy is assumed for the laser beam and the spatial dependent heat generation rate in every layer could be written as [18]

$\mathrm{Q}(\mathrm{x}, \mathrm{y})=\left(\mathrm{E}_{\alpha(\mathrm{j})} /\left(\pi \mathrm{r}_{\mathrm{jx}} \mathrm{r}_{\mathrm{jy}} \mathrm{d}_{\mathrm{j}}\right)\right) \exp \left(-\left(\mathrm{x} / \mathrm{r}_{\mathrm{jx}}\right)^{2}-\left(\mathrm{y} / \mathrm{r}_{\mathrm{jy}}\right)^{2}\right)$.

wherein, $r_{j y}=r_{b}=0.5 \mathrm{~mm}$ is identical for each layer while $r_{j x}$ could be roughly formulated by considering the exponential attenuation of the laser propagated in the jth layer media as

$r_{j x}=\left(r_{b} / \cos \left(\theta_{j}\right)\right)\left(1+\exp \left(-\alpha_{j} d_{j} / 2\right)\right) /\left(1-\exp \left(-\alpha_{j} d_{j} / 2\right)\right)$.

The center of the elliptical spot at the surface directly irradiated by the laser beam is located at the point $(0,0,0)$. To be noted that the heat generation rate, $Q$ within every layer would be independent of $z$, the coordinate along the thickness of the cell as the effect of the interferences on the energy distribution of laser within each layer has not been considered in the present model.

By solving the Fourier heat conduction equation

$\frac{Q}{k}+\Delta T_{e m p}=\frac{1}{\beta} \frac{\partial T_{e m p}}{\partial t}$,

controlling the temperature of each layer with thermal continuity conditions at every interface as well as the thermal boundary conditions 
Table 3

Constants for the material model.

\begin{tabular}{llllll}
\hline & $\mathrm{i}=0$ & $\mathrm{i}=1$ & $\mathrm{i}=2$ & $\mathrm{i}=3$ & $\mathrm{i}=4$ \\
\hline $\mathrm{c}_{\mathrm{ki}}$ & 379 & -2.04 & $4.61 \mathrm{e}-3$ & $-4.79 \mathrm{e}-3$ & $1.82 \mathrm{e}-9$ \\
$\mathrm{c}_{\mathrm{\rho} i}$ & 4816 & -0.10 & $6.06 \mathrm{e}-5$ & $-3.43 \mathrm{e}-8$ & 0 \\
$\mathrm{c}_{\mathrm{ci}}$ & 279 & 0.10 & 0 & 0 & 0 \\
\hline
\end{tabular}

$\mathbf{q}_{1}=\varepsilon_{i e} \sigma\left(T_{e m p}^{4}-T_{a m b}^{4}\right)$,

and

$\mathbf{q}_{2}=h \cdot\left(T_{e x t}-T_{e m p}^{4}\right)$.

at the outermost surfaces of the cell with constants $\varepsilon_{\mathrm{ie}}=0.85$, $\mathrm{h}=25 \mathrm{Wm}^{-2} \mathrm{~K}^{-1}$ and $\mathrm{T}_{\mathrm{amb}}=\mathrm{T}_{\text {ext }}=293.15 \mathrm{~K}$.

It is noteworthy that the temperature-dependent model are used for the thermos-physical properties of the 01st, 02nd, 03rd, 05th and 07th layers as

$\mathrm{k}=c_{k 0+} \sum_{i=1}^{4} c_{k i} T_{e m p}^{i}$

$\rho=c_{\rho 0+} \sum_{i=1}^{3} c_{\rho i} T_{e m p}^{i}$

and

$\mathrm{c}=c_{c 0+} c_{c 1} T_{e m p}$.

For those layers the average magnitudes of the corresponding thermal properties [19-21] are listed in Table 2 and the constants in the models of (52), (53) and (54) are listed in Table 3.

The thermal insulation boundary condition is assumed at the symmetrical surface and the uniform initial temperature are set as $293.15 \mathrm{~K}$. The heat conduction equation was solved through $20 \mathrm{~s}$ with time step of $0.01 \mathrm{~s}$. Under the above conditions, the typical temperature profile could be obtained as shown in Fig. 8. The peak temperature elevation region of elliptical shape could be observed on both the front surface and back surface.

The temperature histories of two points on the directly irradiated front surface, center point of the beam spot with coordinates $(0,0,0)$ and edge point of the beam spot $\left(r_{b}, 0,0\right)$ are shown in Fig. 9. It is indicated that the temperature would increase sharply when the laser irradiation is turn on and then gradually approach to some steady magnitude, when the heat generated by laser irradiation could be diffused into the environment through convection and radiation.

The temperatures of the center nodes on different layers at four

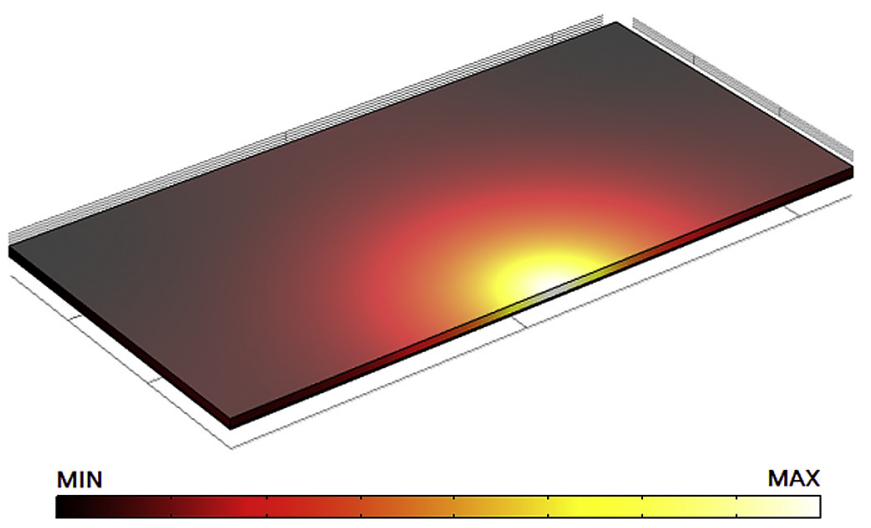

Fig. 8. Typical temperature profile.

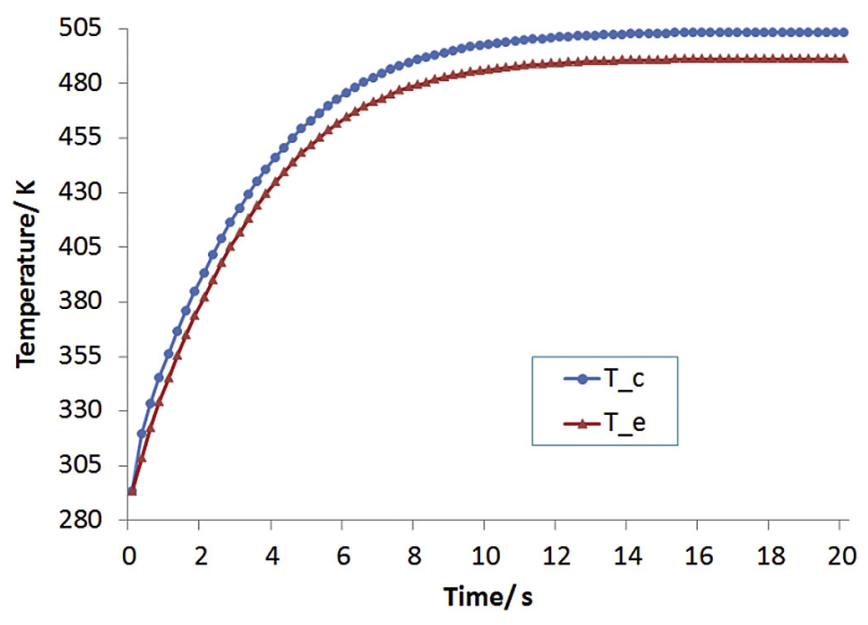

Fig. 9. Temperature history of two surface points.

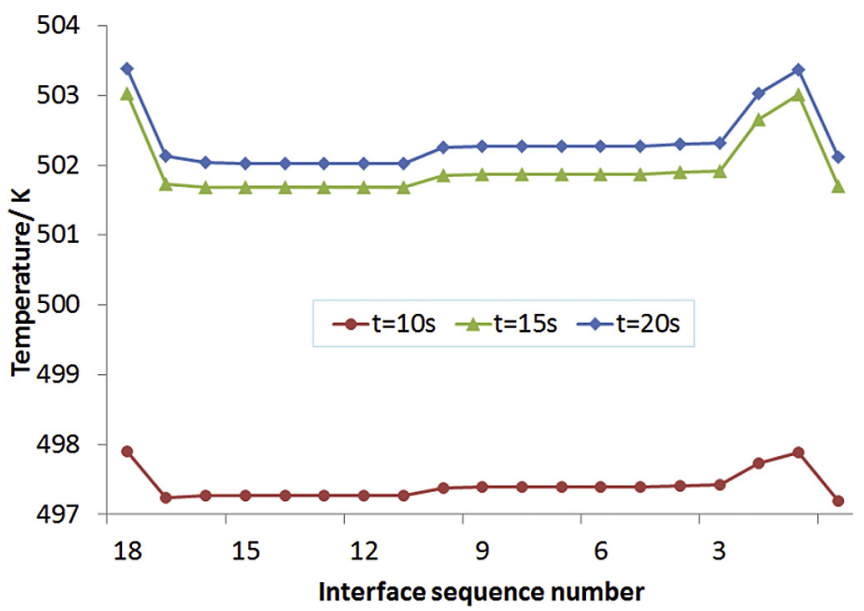

Fig. 10. Temperature mapped onto the central paths along z-axis.

typical instants, those are $t=10 \mathrm{~s}, 15 \mathrm{~s}$ and $20 \mathrm{~s}$ were mapped onto a vertical center path and shown in Fig. 10, in which the horizontal coordinate refers to the interface sequence number counted from the front face.

It is noteworthy that the nodes are deliberately arranged at the interfaces or surfaces, thus not uniformly distributed along the central axis in Fig. 10. It is revealed that one of the temperature crests appears at the subsurface nodes even after the cell approaches to the stable state under laser irradiation, which should be resulted from the fact that the absorption peak appear around the subsurface. It might also be partially resulted from the nonlinear thermal behaviors of the materials utilized in the computation. In particular, the temperature-dependent thermal conductivity of the materials should attribute to the nonlinear temperature elevation versus time.

It is also indicated that the temperatures of the inner interface along the central axis are slightly lower than that of the surface or subsurface. Therefore, the heat generated in the region where the input laser energy dissipated would diffuse along the directions parallel the interfaces at the beginning. This is validated by the steady-state temperature gradient mapped onto the path along $\mathrm{x}$ axis that originated at the central point $(0,0,0)$ and ended at point (10.8r $\left.\mathrm{r}_{\mathrm{b}}, 0,0\right)$, as shown in Fig. 11.

It is revealed the temperature gradient is always negative, which means that the temperature always decreases with the increasing 


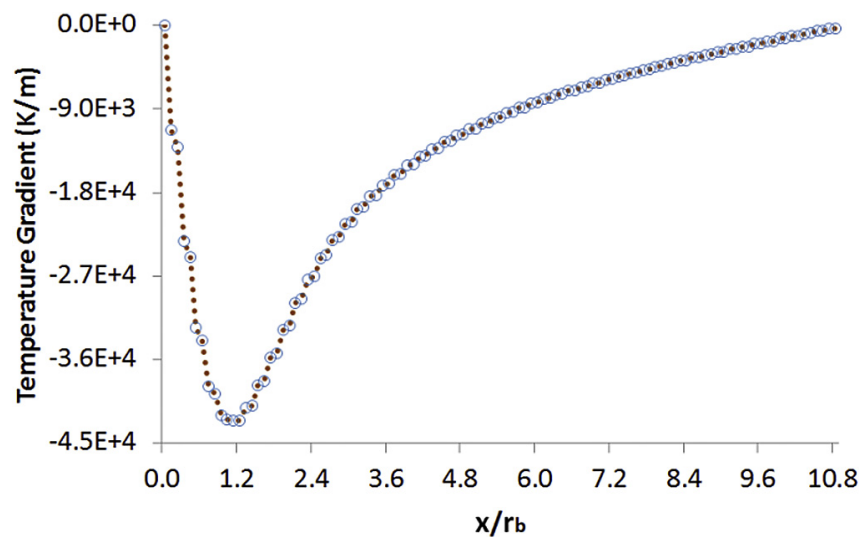

Fig. 11. Temperature gradient mapped onto the path along $\mathrm{x}$-axis.

of the distance from the central point of the laser beam spot. Obviously, the slight difference in temperature within a small structure might develop large temperature gradient. It is also noteworthy that the maximum temperature gradient arises around the edge of the laser spot, which might be crucial for thermomechanical analysis.

It is noteworthy that the present model does not explicitly include the light scattering effect as the homogeneity and ideal geometry have been assumed herein, although the referenced refractive indexes of the materials might have accounted partly for the scattering [17]. There are inevitably other kinds of scattering of the incident light wave, or photons in the semiconductors, which would also make the ray paths more complicated and change the spatial distribution of light absorption. Therefore, the temperature characteristic of the photovoltaic cell under laser irradiation might subject to slight alteration. As far as the multiple scattering is mainly taken into account, the concentration of laser absorption as well as heat generation would usually be reduced and the peak temperature gradient would be decreased.

\section{Conclusions}

The monochromatic light transfer in a multijunction photovoltaic cell is formulated with considering the multiple reflections and interference. The absorptions of incident laser energy in every layer of the cell are calculated via an iterative algorithm. The overall absorption of laser energy depends largely on the incident angle and maximized at some specific incident angle before abruptly reduced to zero for the case of incident angle $90^{\circ}$. The computational results reveal that large fraction of the laser energy is absorbed by some inner layer. The total absorbed energy almost increases with the decreasing in wavelength of the incident laser. The finite element analysis reveals that the peak temperature arises in the subsurface layer and the maximum temperature gradient arises around the edge of region covered by laser spot.

\section{Acknowledgements}

This work was supported by the National Natural Science Foundation of China (Grant No. 11572327 and No. 11332011).

\section{References}

[1] Green M. Solar cells: operating principles, technology, and system applications. New Jersey: Englewood Cliffs; 1982.

[2] Singh P, Ravindra NM. Temperature dependence of solar cell performance-an analysis. Sol Energy Mater Sol Cells 2012;101:36-45.

[3] Ben Or A, Appelbaum J. Dependence of multijunction solar cells parameters on concentration and temperature. Sol Energy Mater Sol Cells 2014:130:234-40.

[4] Fernandez Eduardo F, et al. Multijunction solar cells electrical characterization by neuronal networks under different irradiance, spectrum and cell temperature. Energy 2015;90:846-56.

[5] Meneses-Rodriguez D, et al. Photovoltaic solar cells performance at elevated temperatures. Sol Energy 2005;78(2):243-50.

[6] Da Yun, et al. From light trapping to solar energy utilization: a novel photovoltaicethermoelectric hybrid system to fully utilize solar spectrum. Energy 2016:95:200-10.

[7] Skoplaki E, Palyvos JA. On the temperature dependence of photovoltaic module electrical performance: a review of efficiency/power correlations. Sol Energy 2009;83(5):614-24.

[8] Yang MD, et al. Measuring junction temperature of GaAs solar cells using pulse-width modulation photoluminescence. Solid State Commun 2010;150(27-28):1217-20.

[9] Jiang J-A, et al. Analysis of the junction temperature and thermal characteristics of photovoltaic modules under various operation conditions. Energy 2012;44(1):292-301.

[10] Mavromatakis F, et al. Measuring and estimating the temperature of photovoltaic modules. Sol Energy 2014;110:656-66.

[11] Docimo DJ, et al. Extended Kalman Filtering to estimate temperature and irradiation for maximum power point tracking of a photovoltaic module. Energy 2017;120:47-57.

[12] Caluianu I-R, Băltăreţu F. Thermal modelling of a photovoltaic module under variable free convection conditions. Appl Therm Eng 2012;33-34:86-91.

[13] Lee Y, Tay AAO. Finite element thermal analysis of a solar photovoltaic module. Energy Proced 2012;15:413-20.

[14] Zhou J, et al. Temperature distribution of photovoltaic module based on finite element simulation. Sol Energy 2015;111:97-103.

[15] Theristis M, O'Donovan TS. Electrical-thermal analysis of III-V triple-junction solar cells under variable spectra and ambient temperatures. Sol Energy 2015; 118:533-46.

[16] Yuan Yu-Chen, Wu Chen-Wu. Thermal analysis of film photovoltaic cell subjected to dual laser beam irradiation. Appl Therm Eng 2015;88:410-7.

[17] Born Max, Wolf Emil. Principles of optics. seventh ed. Cambridge University Press; 2005.

[18] von Allmen Martin. Laser-beam interactions with materials: physical principles and applications. Springer Press; 1987.

[19] Weber Marvin J. Handbook of optical materials. CRC Press; 2003.

[20] Wakaki Moriaki, Kudo Kei, Shibuya Takehisa. Physical properties and data of optical materials. Taylor \& Francis Group CRC Press; 2007.

[21] Adachi Sadao. Properties of semiconductor alloys: group-IV, III-V and II-VI semiconductors. John Wiley \& Sons; 2009. 